\title{
A Study on the Comparison of Kyrgyz and Turkish University Students in Terms of Anger Expression Styles, Humor and Obedience
}

\author{
Hasan Yılmaz \\ Kyrgyz-Turkish Manas University, 720044, Bishkek, Kyrgyzstan
}

Copyright $\bigcirc 2018$ by authors, all rights reserved. Authors agree that this article remains permanently open access under the terms of the Creative Commons Attribution License 4.0 International License

\begin{abstract}
The aim of this study is to compare Kyrgyz and Turkish students in terms of styles of anger, anger expression, humor, and obedience. The scales for anger expression styles, humor styles, and obedience were applied to 206 Kyrgyz and 197 Turkish students. The greatest differences were found in obedience. Turkish students' continuous anger and anger control scores were significantly higher than those of Kyrgyz students. Although no difference was found in progressive humor, there are significant differences between students from two countries in participatory, offensive, and self-annihilatory humor styles. The findings obtained in the study are compared with the findings of other studies of aggression, humor, and obedience in different cultures and suggestions were made.
\end{abstract}

Keywords Obedience, Aggression, Humor, Turkish, Kyrgyz

\section{Introduction}

Obedience, aggression, and humor are behaviors that are seen quite often in daily life and that are considered related to each other. While they are sometimes the roots of problems in human relations and personal relations, they are problem-solving methods at other times. It can be said that these three emotion-based behaviors are universal for all human beings. Besides, it is accepted that there are cultural sub-structures of anger, obedience, and humor. It may well be claimed that there are personal differences especially in terms of the expression style but it is a fact that there are intercultural differences. It is important that anger, obedience, and humor styles, which pervade a great space in the personal characteristics of individuals, are known so that people in different cultures know each other, establish and continue to have a healthy communication and relationship, and live together.

Resulting from being hurt in social life, ill treatment, or being wronged, anger is an unpleasant and disturbing mood, which has a definite frequency, density, duration, expression style, and tolerance threshold [1]. Like other emotions, anger is quite natural, universal, constructive, and able to organize interpersonal relations when expressed healthily. Although it is a normal emotion that manifests in different stages and densities from frequently experienced little disappointments to heavy rages and is accompanied by physiological and biological changes, the important point is how anger is expressed and managed [2].

Spielberger [3] discusses anger at two dimensions as continuous anger and situational anger. He mentions that situational anger is a mood reflecting tension, furiousness, irritation, and rage against the condition where the intended behavior is prevented or where injustice is perceived. He defines continuous anger as a concept that reflects the frequency at which the situational anger is experienced [4].

Various theories have explanations related to anger. Biological theories focus on the way autonomous nervous system directs anger behavior [5]. The behaviorist theory handles anger together with being obstructed and aggression [6]. The existentialist approach explains it as a human's reaction against extinction, uncultivated potential, and the meaninglessness of life [4]. Rationalist emotional approach treats it as a product of illogical thoughts. According to Ellis, emotions are, to a great degree, the products of human thoughts [7]. According to psychoanalytic theory, anger is rooted in the anal phase. According to Freud, feces is synonymous with anger and is the main vehicle in child's expressing emotions of anger [8]. In Social Learning Theory, behaviors of anger are reactions learnt by modeling, imitation, identification, and reinforcement in terms of their expression [9]. Selection Theory claims that it is an emotion that should be kept under control in a way that will contribute into the development of the individual and emphasizes the importance of the individual's recognition, acceptance, and expression of the feeling of anger [10]. In the inhibition-aggression hypothesis, it is said that aggressive 
behaviors are a reaction against the inhibitions in the environment [11]. The common emphasis of all theories is that coping with anger requires that it should be recognized, not suppressed or hidden. Recognition of anger requires that the biological structure causing anger and affecting anger expression, the individual's logical and illogical beliefs, and the environmental factors such as family, society and culture are known.

Humor is the only creative action field where a signal at a high level of confusion creates a huge reaction at a physiological level [12]. At the level it is created as well as it is interpreted, humor refers to intellect and systematic thought unity. According to Einstein, humor is the thought that laughs. From another aspect, humor is an art that emphasizes the funny and unusual characteristics of some aspects of reality.

There are theories aimed at explaining humor in the literature. Superiority Theories see what makes us laugh as the other people's faults [13]. Incongruity Theories consider humor as the union of incongruous or conflicting thoughts or conditions or as an expression style for thoughts or conditions different from usual rules [14]. According to Psychoanalytic Theory, pleasure in jokes arises due to saving the expenditure of inhibition, in laughter arises due to savings in thinking, and in humor due to savings in emotion. All three of them unite in representing the methods of obtaining a pleasure, which is actually lost through the development of the activity.

There are positive and negative consequences of using humor. An intimacy may form among people through humor. Besides, it contributes to developing an understanding among the group members about what is acceptable and what is unacceptable. This is positive function of humor [15]. Humor plays a conflict-decreasing role in groups where members share their ideas through jokes. Nevertheless, there are authors who draw attention to the negative aspect of humor. In some conditions, humor is used as a defense against racism and being prejudiced. According to superiority theory, joking about other people's stupid acts, teasing and laughing form the basis of humor experience [16].

Obedience is defined as a set of personality traits which are characterized by behaviors such as paying attention not to hurt other people, trying to please everyone, being helpful, being unable to say "no", having difficulty in expressing the conditions that $\mathrm{s} /$ he does not like, having difficulty in expressing one's anger, feeling the need to be confirmed all the time, being unable to defend one's rights [17].

The reason why individuals show obedient behavioral traits is the parental attitudes that are high-disciplined, oppressive and over-restrictive [18]. When the individual becomes adult, obedience is a method of avoiding such descriptions as worthless, evil, unlikeable, selfish, which are attributed by the individual himself/herself or by others. The fears about being unlike, rejected, or humiliated direct the individual towards the behavior of obedience [19].

The previous studies about obedience behavior use one of the following two theories: the Social Dominance Theory and the Authoritarian Personality Theory. The Social Dominance Theory uses the concept of adaptation to social dominance and mentions that this is a general behavioral adaptation. It claims that the individuals whose levels of adaptation to social dominance are high show tendency towards thought systems that increase hierarchy whereas the individuals whose levels of adaptation to social dominance are low show tendency towards thought systems that decrease hierarchy [20]. According to the Authoritarian Personality Theory, obedience attitude occurs as a result of authoritarian and cruel parental attitudes. The child learns to obey in order to solve the conflict between him/her and his/her parents. When he/she becomes an adult, he becomes a type of person who obeys the authority and who does not tolerate people that do not act in the same way [21]. As a result of failures in developing inner conscience, the personality that believes in the power of authority and in obeying this power shows characteristics that are idealized as the orientation towards emotional need and internalized obedience to authorities [22].

When these two theories are examined, the explanation of Social Dominance Theory about adaptation to social dominance and the explanation of Authoritarian Personality Theory about believing in the power of authority seem to support each other. It is possible to find explanations about obedience in some other theories. For example, "appropriate child ego status", which is among the ego states in Transactional Analysis, shows similarities with obedient structure [23]. It is possible to see many explanations about the subject in Erich Fromm's work too. Fromm defines obedience as an escape from the "basic insecurity" which disobedience will cause [24].

There are studies showing that the three concepts explained above differ from one culture to another. It is a fact that anger, humor, and obedience have social and cultural bases as well as biological and personal bases. Every person is born into a culture and acquires behavioral patterns in that culture through social learning. People can establish and continue healthy relations to the degree to which they know and pay attention to each other's understanding and expression styles about anger, humor, and obedience in intercultural interaction and communication process. In this study, the continuous anger levels, anger expression styles, positive and negative humor understandings, and obedience characteristics of individuals who grow up and live in two different cultures were compared.

The objective of this study was to characterize and compare Kyrgyz and Turkish university students within the framework of the above-mentioned theories on anger, humor, and obedience. Determining whether Kyrgyz and Turkish university students show significant differences in 
terms of continuous anger, anger expression, humor styles, and obedience forms the general objective of the study. Within the framework of this general objective, the following questions were asked:

1. Is there a significant difference between Kyrgyz and Turkish university students in terms of continuous anger and anger expression styles?

2. Do Kyrgyz and Turkish university students' anger and anger expression styles show differences according to sex?

3. Is there a significant difference between Kyrgyz and Turkish university students in terms of their humor style?

4. Do Kyrgyz and Turkish university students' humor styles show differences according to sex?

5. Is there a significant difference between Kyrgyz and Turkish university students in terms of obedience?

6. Do Kyrgyz and Turkish university students' obedience styles show differences according to sex?

\section{Literature Review}

Here, the studies on the intercultural comparisons of anger, humor, and obedience were reviewed, with more attention to recent ones.

In a study based on the assumption that United Kingdom and Finland, Turkey and Pakistan, and Hong Kong and China represent three different cultures [25], it was found that suppressing and controlling anger was believed to harm honour in the sample from United Kingdom and Finland whereas it indicates superiority and nobility in the other cultures. In a study where the relationship between not expressing and suppressing anger and high depression and low life satisfaction was investigated, it was concluded that Spielberg's Anger Expression Inventory had intercultural validity and that it was a suitable means in understanding cultural differences in anger and the ways it is expressed.

A previous study, which focused on samples from Germany, Israel, Greece, and USA, was based on the assumption that understanding the expressions of feelings correctly determines the reaction to be given, which in turn makes the communication more efficient and useful [26]. In this study where the reactions given and the meanings ascribed to expressions of anger, sorrow, and neutral emotions were compared; intercultural differences were observed among four sample groups in agreement with the proposed hypothesis. In this study, it was found that the expressions of anger and sorrow were perceived by German and Israel samples relatively more correctly, and it was emphasized that the expression of anger had both cultural and universal bases. In another study examining the role of culture on the manner of expressing anger, comparisons were made between the Chinese and the Americans [27]. It was found that the Americans expressed their anger directly and Chinese tended to stay away from anger and to express anger in a less direct way. This situation was considered to result from the culture of collectivism dominant in the Chinese society. The study emphasized that both tendencies had advantages and disadvantages, and it was mentioned that anger and its expression show differences depending on the culture and that it was necessary to learn the cultural context in order to understand anger and its expression. In addition, it was also highlighted that the culture is not static and the expression and interpretation of feelings may change in time.

In another study on samples from Indonesia and Australia [28], it was concluded that anger expression styles show differences for these two groups and, yet, anger expression styles between the children and mothers were completely similar. In the Australian families, it was observed that shouting, screaming, and breaking things were the most common anger expression behaviors in both parents and children. In Indonesia on the other hand, both parents and children were found to be inclined to talk calmly and to solve the problem in private when they got angry. The researchers explained this situation by pointing to the individualist and liberal culture of Australia and the collectivist culture of Indonesia.

In a study with samples from the USA and Japan [29], it was determined that anger is experienced as a result of disappointments in the USA whereas it was experienced as a show of power in Japan. It was observed that expressing anger became easier as social status increased and that the sample from the USA considered anger as a more private social condition while the Japanese sample saw anger as an expression of social status.

In a study with samples from the USA and Belgium [30], it was determined that there were similarities in the responses given to the words expressing anger and that anger strongly suggested aggression in the sample from the USA while Belgian sample attributed meanings that are away from aggression. The study showed that the perception was determined by and reflected according to the culture's emotional sets. Researchers mentioned that the Americans had perceptions and reactions compatible with the competitive and individualistic culture and with the aims of this culture while the expression of anger was not endorsed in the Belgian culture; and they also supported this view by the descriptions expressing anger in the books of two cultures.

The intercultural equivalence of emotions and cultural differences were examined in a multicultural group in Latin America [31]. In this study where it was determined that the psychological structures of anxiety, anger, and depression showed similarities, these emotions were suggested to be the universal products of evolution. The researchers based this view on Darwin's remark that worry and anger were the common trait of humans and animals and the basis of their motivation for survival. In 
the same study, the need for tools of measuring emotions free from cultural influences and the difficulties in obtaining such tools were emphasized.

In an experimental study where the effect of the anger behavior displayed by the European-Americans an Asian-Americans during an online discussion on each other was observed, it was determined that the European-Americans got more concessions through anger compared to Asian-Americans and that they were affected less by the other party's anger behavior [32]. The study showed that anger behavior had different effects on people from different cultures and that the European-Americans manipulated anger in a more suitable way.

In a study where Indian students and Iranian students were compared [33], significant differences were observed between two groups in terms of their anger expression styles. It was determined that Iranian women scored higher in the dimension of continuous anger and Indian women scored higher in the dimension of anger control. In the same study, it was determined that Indian students scored significantly higher than Iranian students in anger control.

In another comparative study [34], a higher continuous anger level was observed among Israeli women compared to Israeli men. American students also had this gender disparity in continuous anger.

Humor has been the subject of many studies. Apart from the studies investigating the relationships between demographic variables and humor, the studies on this subject can be summarized as follows:

$\begin{aligned} \text { i. } & \text { Humor and Physical Health [35], } \\ \text { ii. } & \text { Humor, Psychological Well-Being and } \\ & \text { Psychopathology [36], } \\ \text { iii. } & \text { Humor, Positive Psychology and Life Quality } \\ & {[37], } \\ \text { iv. } & \text { Humor, Personality and Other Personal Differences } \\ & {[38], } \\ \text { v. } & \text { Humor and Development Matters [39], } \\ \text { vi. } & \text { Humor and Intercultural Matters [40], } \\ \text { vii. } & \text { Humor and Behaviour Genetics [41], } \\ \text { viii. } & \text { Humor in Social Relations and Close Relations [42] } \\ & \text { end }\end{aligned}$

ix. Humor as a Technique of Intervention [43].

We have very little knowledge about how culture shapes the perceptions of humor. However, the studies on the opinion that the meaning and style of humor differ in the Eastern and Western cultures increase in recent years. While Westerners see humor as a common and positive tendency for all humans, Easterners consider humor as a profession unique to the people who become specialist on this matter. For instance while the Canadians expect common people to have sense of humor, the Chinese expect professional comedians to have sense of humor. At the same time, many Western authors have considered humor as a way of coping with problems. It can be said that this view dates back to the period of Platon and
Aristotle in the Western cultures. The 20th century is considered as the golden age of humor especially for American society [44].

In many studies involving intercultural comparison as related to humor, the Chinese sample and the American and Canadian samples are compared. In the overall evaluation, it was found that American university students mention humor with positive adjectives and see it as an indispensable part of daily life while Chinese university students use negative adjectives and see humor far from seriousness [45].

In yet another study from China [46], the results obtained were compared with the results of a Canadian sample. In the study, it was determined that the Chinese subjects scored significantly lower than the Canadians, especially in aggressive humor, but no significant difference was found between men and women. In the Canadian sample, it was observed that men used aggressive and self-annihilating humor more often than women. In both Chinese and Canadian samples, young participants were found to use humor more often than older ones. While it was observed that aggressive and self-progressive humor types were related to the General Symptomatic Index, a sub-scale of SCL-90, in a positive way, there is negative correlation with the participatory and self-progressing humor types. In the same study, it was emphasized that there was a significant relationship between mental health and humor.

In a study examining the relationship between cultural values and humor types [40], a significant difference was observed between individualistic and collectivist lifestyles especially in terms of the participatory and self-progressive humor. In this study, culture was found to explain $11.25 \%$ of the total variance for four humor types on average.

Apart from the study of the Chinese sample, the humor types of the Armenian society living in Lebanon were examined and the results were compared to those obtained in other cultures [47]. It was determined that Armenian-Lebanese participants scored lower in all participatory, self-progressive, aggressive, and self-annihilatory humor types than the Canadian and Belgian participants. In the study, it was found that men use aggressive and self-annihilatory humor types more often in particular. In addition to these findings, no correlation was found between humor types and depression while significant relation was found between the perceived health condition and psychological well-being variables. The researchers also mentioned that the Humor Types Scale used in our study as well was suitable for making intercultural comparisons.

There are many studies that deal with humor apart from the cultural comparisons. The relation of especially happiness with self-progressive and participatory humor types has been found as well as a relationship between the humor types and the personality traits, which include extroversion, control focus, optimism, ego respect, and 
happiness, was investigated. In the study, a negative relationship was observed between happiness and the self-annihilatory and aggressive humor types; the researchers interpreted this as the individuals with higher scores of extroversion, control focus, ego respect, and optimism were happier since they had positive humor understanding [48].

In a similar study, a positive relationship between self-progressive humor and empathy was found while a negative relationship was found between aggressive humor and empathy [49]. In a study investigating the relationship between humor types and cognitive distortion and depression [50], it was determined that the cognitive distortion and depression levels are lower in those who use the participatory and self-progressive humor; however, they are at a higher level in those using the aggressive and self-annihilatory humor. In another study that supports these findings [51], negative significant relationships were found in the pathological personality characteristics in DSM-5 and the positive humor types while positive significant relationships were found with the negative humor types. Fox [52] have conducted a study that found humor related to psycho-social adaptation in teenage period [52]. The relationship between humor and the characteristics of interpersonal relations and the harmony between partners has been the subject of several studies. In a study, which found that the individuals producing positive humor have long-term relations while those using negative humor have shorter and superficial relations [53], it was determined that individuals having positive humor understanding have higher social attraction. In another study, which examined the relationship between humor types and the quality of the relationships among married and divorced individuals [54], it was found that the satisfaction obtained from marriage was high in individuals with similar humor types and that using the participatory and self-progressive humor was low among the divorced couples. Hahn and Campbell [55] found that there were significant similarities between humor types of individuals who had happy marriages. In the same study, it was found that the similarity between the humor types of couples who had high ego respect was higher [55].

The three fundamental and important studies in the literature are Sherif's experiment of "The Formation of Group Norm", Asch's experiment of "Adaptation" and Milgram's experiment of "Obedience". Although there are several other studies about obedience, these three studies were chosen as basis in almost all studies.

Freedman, Sears, and Carlsmith [56] examined the effect of obedience expectation and behavior on the obedient individual. The authority's any behavior that will cause individual to feel more responsibility for his/her own behavior decreases obedience. Yet, each factor that emphasizes negative aspect of obedience has an effect on the individual that will decrease the action of obedience [56]. Considering the obedience as obeying the wishes of the authority, Aronson, Wilson and Akert [57] have determined that the emergence of obedience depends on three factors. The first is that the individual's obedience to these wishes is shown as if this behavior were the best action. They called this "communicative effect". The second one is that the individual's obedience so that $\mathrm{s} / \mathrm{he}$ is not rejected but approved by others and they called this as "normative effect". The last one is that the individual accepts authority's social norms without questioning, which is called "unconscious adaptation" [57]. Hennessy and Wiesenthal [58] have determined that adaptation and obedience decrease as the individual's knowledge and ability on a subject increase [58]. In a similar study, Campbell [59] has concluded that the people who are not self-confident show more adaptation and obedience behavior than those who are self-confident [59].

The studies on obedience and submission have recently been increasingly more common. The researchers try to determine the principles of obedience and adaptation that can be generalized by using various experimental settings and instruments. Unlike hundreds of other obedience studies done until recently, a study utilized a robot designed as a security guard and gave orders to people [60]. In the study, four factors affecting a person's decision to obey the order of the robot have been determined: the perceived aggression in the robot's behavior, anthropomorphism (the tendency to attribute human behaviors to another entity), the security level of the environment, and intelligence. While it is observed that some people's obedience to robot's instructions increase according to the perceived aggression in robot's behaviors, this has no significant effect in some others. It is mentioned in the findings of the same study that those who follow robot's orders are less self-confident than the others.

In a study published last year, it was claimed that two basic factors determine the obedience behavior in humans [61]. The first is whether the gender of the person who gives order and is expected to obey the order is same or not, and the second is the tendency to do what is expected of oneself by stopping the search related to the decision that one will make in cases of confusion and ambiguity, which is expressed as tendency to cognitive closing. The condition that the gender of the person giving the order and the person obeys the order is same has increased the effect of the second factor on obedience. This condition is observed to be higher among men than women. Some researchers [21] studied the relation between authoritarian personality characteristic and obedience. Researchers suggested that whether the authority wears uniform or not, personality traits, and the characteristics of the experimental medium are factors that determine obedience irrespective of the subject. In later studies, the view that there is a relation between authoritarian personality and obedience has been accepted but it has also been emphasized that a set of situational variables can affect the level of contribution. Adorno's findings have been supported by other studies. For instance, in a study 
involving nurses and doctors, it was observed that nurses obey a doctor's order even when there is good reason to believe that a potential harm can be done to patients [62] All these discussions gained a new aspect together with Middendorp and Meloen's study [63] determining that individuals with low level of education tend to show authoritarian personality characteristics more than those with high level of education [63]. Then, it is possible under this condition to conclude that not authoritative personality characteristics but the level of education is effective on obedience.

Yet, in the period over 50 years since the original experiments on obedience by Stanley Milgram, the obedience rates of the subjects in all studies have supported Milgram's findings, and higher percentages have been found in some studies. The point that researchers cannot agree on is what the variables affecting this high obedience percentage are. For instance, Dolinski [19] claimed that the subjects' gender and personality characteristics could not be accepted or rejected on obedience [19]. Pozzi [64] have determined that the most important variable is whether the authority is a person, an institution, or social norms [64]. While the same researchers see obedience as an uncritical response to mostly laws, social norms, or physical authorities, they define disobedience as an active and conscious attitude.

Studies on obedience continue as intercultural comparisons. Similar results have been obtained about the obedience rates in all similar experiments performed up to now and no significant difference has been found between the East and West $[65,66]$. However, there are important differences between cultures when the variables affecting obedience are considered.

For instance, the fact that the person to be obeyed has a scientific identity increases the tendency of obedience in the Western cultures, the leader's characteristics such as being a mystical personality or having charismatic characteristics are more important in the Eastern cultures. Blass [67] summarized the obedience rates in various societies in his article where he gathered the intercultural studies up to the present as follows: Italy $85 \%$; South Africa $87.5 \%$; Germany $85 \%$; Australia $28 \%$; Jordan $73 \%$; Spain 50\%; India 42.5\%, and Austria 80\% [67].

\section{Methodology}

Table 1. The information on gender and countries of origin for the students included in the sample.

\begin{tabular}{ccccccc}
\multirow{2}{*}{$\begin{array}{c}\text { Country of } \\
\text { origin }\end{array}$} & \multicolumn{2}{c}{ Male } & \multicolumn{2}{c}{ Female } & \multicolumn{2}{c}{ Total } \\
\cline { 2 - 7 } & $\mathrm{N}$ & $\%$ & $\mathrm{~N}$ & $\%$ & $\mathrm{~N}$ & $\%$ \\
\hline Kyrgyzstan & 98 & 49.3 & 108 & 52.9 & 206 & 51.1 \\
Turkey & 101 & 50.7 & 96 & 47.1 & 197 & 48.9 \\
Total & 199 & 100.0 & 204 & 100.0 & 403 & 100.0 \\
\hline
\end{tabular}

Within this framework, a sample group of 403 students was selected from 4600 Kyrgyz and 650 Turkish students by considering the characteristics related to their school, department, and class. The information about the sample group was given in Table 1.

In addition to personal information form, three scales were used in order to collect data in the study. The descriptions of these scales were given below.

The Turkish version [4] of the state-trait anger scale (STAS), which was developed by Spielberger [3], was used to determine continuous anger and anger expression styles. For continuous anger scale, Cronbach alpha coefficient was found 0.79 ; it was found 0.84 for controlled anger sub-scale, 0.78 for expressed anger sub-scale, and 0.62 for suppressed anger sub-scale.

The second instrument used in our study is Humor Styles Questionnaire (HSQ) revised by Martin, Puhlik-Doris, Larsen, Gray, and Weir [68] and adapted into Turkish by Yerlikaya [14]. The internal consistency Cronbach alpha coefficients for each sub-scale were as follows: 0.74 for participatory humor, 0.78 for self-progressive humor, 0.69 for aggressive humor, and 0.67 for self-annihilatory humor.

The third instrument used in our study was Obedient Behaviors Scale (OBS), which was developed by Gilbert [69] in order to measure social behaviors related to obedience and adapted to Turkish by Savaşır and Şahin [70]. The Cronbach alpha coefficient for this scale was 0.89 and test re-test reliability coefficient was 0.84 . The internal consistency Cronbach alpha was found 0.74 when the scale was adapted to Turkish.

During the analysis of data, independent samples t-test was used to determine if the scale scores differed by country of origin or gender; statistical significance level was set at 0.05 in the interpretation of results.

\section{Findings}

\subsection{Comparison of the Continuous Anger and Anger Expression Styles of the Students from Kyrgyzstan and Turkey}

Findings about the comparison of continuous anger and anger expression styles of the students who were from Kyrgyzstan or Turkey were given in Table 2. As seen in Table 2, the Turkish students' average scores of continuous anger (24.7) and anger control (23.4) were significantly higher than those of Kyrgyz students $(p<0.001)$. This shows that Turkish students have higher level of continuous anger than Kyrgyz students and that they have significant differences in controlling their anger. No significant difference was observed between two groups in suppressed anger and anger expressed 
Table 2. Anger in students of Turkish and Kyrgyz origin.

\begin{tabular}{|c|c|c|c|c|c|c|}
\hline & Country of origin & $\mathbf{N}$ & Average & $\begin{array}{l}\text { Standard } \\
\text { deviation }\end{array}$ & t-value & p-value \\
\hline \multirow{2}{*}{ Continuous anger } & Turkey & 197 & 24.7 & 7.74 & \multirow{2}{*}{-7.306} & \multirow{2}{*}{$.001^{*}$} \\
\hline & Kyrgyzstan & 206 & 17.9 & 5.40 & & \\
\hline \multirow{2}{*}{ Anger suppressed } & Turkey & 197 & 17.8 & 4.14 & \multirow{2}{*}{1.510} & \multirow{2}{*}{.133} \\
\hline & Kyrgyzstan & 206 & 18.6 & 3.61 & & \\
\hline \multirow{2}{*}{ Anger expressed towards others } & Turkey & 197 & 16.4 & 4.40 & \multirow{2}{*}{-0.252} & \multirow{2}{*}{.802} \\
\hline & Kyrgyzstan & 206 & 16.3 & 4.0 & & \\
\hline \multirow{2}{*}{ Anger control } & Turkey & 197 & 23.4 & 4.3 & \multirow{2}{*}{-3.853} & \multirow{2}{*}{$.001^{*}$} \\
\hline & Kyrgyzstan & 206 & 20.8 & 4.9 & & \\
\hline
\end{tabular}

Table 3. Anger in female students from Turkey and Kyrgyzstan.

\begin{tabular}{|c|c|c|c|c|c|c|c|}
\hline & Gender & Country of origin & $\mathbf{N}$ & Average & $\begin{array}{l}\text { Standard } \\
\text { deviation }\end{array}$ & t-value & p-value \\
\hline \multirow{2}{*}{ Continuous anger } & Female & Turkey & 96 & 21.93 & 5.38 & \multirow{2}{*}{-2.223} & \multirow{2}{*}{.028} \\
\hline & Female & Kyrgyzstan & 108 & 19.57 & 5.4 & & \\
\hline \multirow{2}{*}{ Anger suppressed } & Female & Turkey & 96 & 17.13 & 3.66 & \multirow{2}{*}{1.439} & \multirow{2}{*}{.153} \\
\hline & Female & Kyrgyzstan & 108 & 18.10 & 3.22 & & \\
\hline \multirow{2}{*}{ Anger expressed towards others } & Female & Turkey & 96 & 16.54 & 4.32 & \multirow{2}{*}{-0.968} & \multirow{2}{*}{.335} \\
\hline & Female & Kyrgyzstan & 108 & 15.81 & 3.40 & & \\
\hline \multirow{2}{*}{ Anger control } & Female & Turkey & 96 & 23.47 & 4.36 & \multirow{2}{*}{-1.365} & \multirow{2}{*}{.175} \\
\hline & Female & Kyrgyzstan & 108 & 22.43 & 3.46 & & \\
\hline
\end{tabular}

Table 4. Anger in male students from Turkey and Kyrgyzstan.

\begin{tabular}{|c|c|c|c|c|c|c|c|}
\hline & Gender & Country of origin & $\mathbf{N}$ & Average & $\begin{array}{l}\text { Standard } \\
\text { deviation }\end{array}$ & t-value & p-value \\
\hline \multirow{2}{*}{ Continuous anger } & Male & Turkey & 101 & 27.13 & 8.63 & \multirow{2}{*}{7.98} & \multirow{2}{*}{.001} \\
\hline & Male & Kyrgyzstan & 98 & 15.88 & 4.72 & & \\
\hline \multirow{2}{*}{ Anger suppressed } & Male & Turkey & 101 & 18.35 & 4.48 & \multirow{2}{*}{1.0} & \multirow{2}{*}{.33} \\
\hline & Male & Kyrgyzstan & 98 & 19.18 & 3.97 & & \\
\hline \multirow{2}{*}{ Anger expressed towards others } & Male & Turkey & 101 & 16.29 & 4.51 & \multirow{2}{*}{0.57} & \multirow{2}{*}{.57} \\
\hline & Male & Kyrgyzstan & 98 & 16.81 & 4.58 & & \\
\hline \multirow{2}{*}{ Anger control } & Male & Turkey & 101 & 23.25 & 4.37 & \multirow{2}{*}{4.26} & \multirow{2}{*}{.001} \\
\hline & Male & Kyrgyzstan & 98 & 18.92 & 5.72 & & \\
\hline
\end{tabular}

The comparison of female Turkish and Kyrgyz students was given in Table 3. Significant difference $(x=21.93$ and $\mathrm{x}=19.57 ; \mathrm{p}<0.02$ ) was found between female Turkish and Kyrgyz students only in terms of continuous anger; no significant difference was observed in terms of anger suppressed, anger expressed towards others, or anger control.

The comparison of male Turkish and Kyrgyz students was given in Table 4. Similar to the observation in the general group, male Kyrgyz and Turkish students' average scores of continuous anger $(x=27.13 x=15.88 ; p<0.001)$ and anger control $(x=23.25, x=18.92 ; p<0.001)$ were significantly different. Turkish students had higher continuous anger and anger control. In terms of the findings related to anger, Turkish students can be said to have higher scores of continuous anger. Turkish and Kyrgyz female students were relatively more similar in terms of anger than the male students were. Turkish and Kyrgyz male students exhibit more differences between the groups. While suppressed anger and anger expressed towards others were similar among students, it was found that Turkish students control their anger better.

\subsection{Comparison of Humor Styles of the Students from Kyrgyzstan and Turkey}

Findings about the comparison of humor styles of the students who were citizens of Kyrgyzstan or Turkey were presented in Table 5. It was found that there were significant differences between Turkish students and Kyrgyz students in the sub-dimensions of participatory 
humor, aggressive humor, and self-annihilatory humor. The largest difference was observed in self-annihilatory humor (4.66), the second largest difference was observed in aggressive humor (3.58); and the smallest difference, despite being significant, was observed in participatory humor. In the dimension of progressing humor, no significant difference was found between Kyrgyz (33.02) and Turkish (33.97) students $(\mathrm{p}>0.05)$. When we consider participatory humor and self-progressing humor dimensions as positive humor understanding, the difference (3.76) between Turkish (73.71) and Kyrgyz (69.95) students was found significant $(p<0.05)$. When aggressive humor and self-annihilatory humor were grouped as negative humor, the difference (8.24) between the Turkish students (52.26) and Kyrgyz students (52.26) was statistically significant $(\mathrm{p}<0.001)$. A larger difference was found between two student groups in negative humor.
The results for the analysis of the findings about humor according to gender were given in Table 6 and Table 7 . When female Turkish and Kyrgyz students were compared, a significant difference was only observed in aggressive humor among four humor dimensions. At this dimension, the difference (4.08) was found significant between the average of Turkish female students (24.59) and the average of Kyrgyz female students (28.67) $(p<0.003)$. No significant difference was observed in the other dimensions. When participatory humor and progressing humor were considered under the heading of "positive humor", no significant difference was found between Turkish and Kyrgyz female students. When aggressive humor and self-annihilatory humor were categorized under "negative humor", the difference (6.51) between the average of female Turkish students (51.65) and female Kyrgyz students (58.16) was statistically different $(\mathrm{p}<0.004)$

Table 5. Humor in Turkish Citizens and Kyrgyz Citizens

\begin{tabular}{|c|c|c|c|c|c|c|}
\hline & Country of origin & $\mathbf{N}$ & Average & $\begin{array}{l}\text { Standard } \\
\text { deviation }\end{array}$ & t-value & p-value \\
\hline \multirow{2}{*}{ Participatory humor } & Turkey & 197 & 39.74 & 9.21 & \multirow{2}{*}{2.54} & \multirow{2}{*}{$.01 *$} \\
\hline & Kyrgyzstan & 206 & 36.93 & 6.42 & & \\
\hline \multirow{2}{*}{ Progressing humor } & Turkey & 197 & 33.97 & 9.56 & \multirow{2}{*}{0.85} & \multirow{2}{*}{.39} \\
\hline & Kyrgyzstan & 206 & 33.02 & 6.05 & & \\
\hline \multirow{2}{*}{ Aggressive humor } & Turkey & 197 & 25.65 & 7.38 & \multirow{2}{*}{1.63} & \multirow{2}{*}{$.001 *$} \\
\hline & Kyrgyzstan & 206 & 29.23 & 6.27 & & \\
\hline \multirow{2}{*}{ Self-annihilatory humor } & Turkey & 197 & 26.61 & 8.33 & \multirow{2}{*}{3.73} & \multirow{2}{*}{$.05 *$} \\
\hline & Kyrgyzstan & 206 & 31.27 & 6.25 & & \\
\hline \multirow{2}{*}{ POSITIVE HUMOR } & Turkey & 197 & 73.71 & 16.35 & \multirow{2}{*}{2.03} & \multirow{2}{*}{$.04 *$} \\
\hline & Kyrgyzstan & 206 & 69.95 & 9.38 & & \\
\hline \multirow{2}{*}{ NEGATIVE HUMOR } & Turkey & 197 & 52.26 & 12.08 & \multirow{2}{*}{3.37} & \multirow{2}{*}{$.001 *$} \\
\hline & Kyrgyzstan & 206 & 60.5 & 10.06 & & \\
\hline
\end{tabular}

Table 6. Humor in Female Students from Turkey and Kyrgyzstan.

\begin{tabular}{|c|c|c|c|c|c|c|c|}
\hline & Gender & Country of origin & $\mathrm{N}$ & Average & $\begin{array}{c}\text { Standard } \\
\text { Deviation }\end{array}$ & t-value & p-value \\
\hline \multirow{2}{*}{ Participatory humor } & Female & Turkey & 96 & 39.52 & 9.2 & \multirow{2}{*}{-0.931} & \multirow{2}{*}{.35} \\
\hline & Female & Kyrgyzstan & 108 & 38.05 & 6.89 & & \\
\hline \multirow{2}{*}{ Progressing humor } & Female & Turkey & 96 & 34.98 & 8.52 & \multirow{2}{*}{-0.992} & \multirow{2}{*}{.32} \\
\hline & Female & Kyrgyzstan & 108 & 33.48 & 6.86 & & \\
\hline \multirow{2}{*}{ Aggressive humor } & Female & Turkey & 96 & 24.59 & 7.43 & \multirow{2}{*}{3.085} & \multirow{2}{*}{$.003 *$} \\
\hline & Female & Kyrgyzstan & 108 & 28.67 & 6.08 & & \\
\hline \multirow{2}{*}{ Self-annihilatory humor } & Female & Turkey & 96 & 27.07 & 7.35 & \multirow{2}{*}{1.748} & \multirow{2}{*}{.083} \\
\hline & Female & Kyrgyzstan & 108 & 29.48 & 6.72 & & \\
\hline \multirow{2}{*}{ POSITIVE HUMOR } & Female & Turkey & 96 & 74.5 & 15.25 & \multirow{2}{*}{-1.801} & \multirow{2}{*}{.241} \\
\hline & Female & Kyrgyzstan & 108 & 71.53 & 10.3 & & \\
\hline \multirow{2}{*}{ NEGATIVE HUMOR } & Female & Turkey & 96 & 51.65 & 12.94 & \multirow{2}{*}{2.941} & \multirow{2}{*}{$.004^{*}$} \\
\hline & Female & Kyrgyzstan & 108 & 58.16 & 9.6 & & \\
\hline
\end{tabular}


in Terms of Anger Expression Styles, Humor and Obedience

Table 7. Humor in male students from Turkey and Kyrgyzstan.

\begin{tabular}{|c|c|c|c|c|c|c|c|}
\hline & Gender & Country of origin & $\mathrm{N}$ & Average & $\begin{array}{c}\text { Standard } \\
\text { Deviation }\end{array}$ & t-value & p-value \\
\hline \multirow{2}{*}{ Participatory humor } & Male & Turkey & 101 & 39.94 & 9.3 & \multirow{2}{*}{-2.801} & \multirow{2}{*}{$.006^{*}$} \\
\hline & Male & Kyrgyzstan & 98 & 35.58 & 5.59 & & \\
\hline \multirow{2}{*}{ Progressing humor } & Male & Turkey & 101 & 33.06 & 10.41 & \multirow{2}{*}{-0.363} & \multirow{2}{*}{.72} \\
\hline & Male & Kyrgyzstan & 98 & 32.46 & 4.92 & & \\
\hline \multirow{2}{*}{ Aggressive humor } & Male & Turkey & 101 & 26.61 & 7.27 & \multirow{2}{*}{2.366} & \multirow{2}{*}{$.02 *$} \\
\hline & Male & Kyrgyzstan & 98 & 29.89 & 6.5 & & \\
\hline \multirow{2}{*}{ Self-annihilatory humor } & Male & Turkey & 101 & 30.0 & 7.1 & \multirow{2}{*}{0.819} & \multirow{2}{*}{.42} \\
\hline & Male & Kyrgyzstan & 98 & 31.23 & 7.81 & & \\
\hline \multirow{2}{*}{ POSITIVE HUMOR } & Male & Turkey & 101 & 73.0 & 17.4 & \multirow{2}{*}{1.809} & \multirow{2}{*}{.07} \\
\hline & Male & Kyrgyzstan & 98 & 68.04 & 7.83 & & \\
\hline \multirow{2}{*}{ NEGATIVE HUMOR } & Male & Turkey & 101 & 56.61 & 10.85 & \multirow{2}{*}{2.107} & \multirow{2}{*}{$.03 *$} \\
\hline & Male & Kyrgyzstan & 98 & 61.12 & 10.46 & & \\
\hline
\end{tabular}

Table 8. Submission (Obedience) characteristics of students from Turkey and Kyrgyzstan

\begin{tabular}{|c|c|c|c|c|c|c|}
\hline Gender & Country of origin & $\mathrm{N}$ & Average score & Standard deviation & t-value & p-value \\
\hline Male & Turkey & 101 & 36.29 & 12.11 & \multirow{2}{*}{3.551} & \multirow{2}{*}{$0.001 *$} \\
\hline Male & Kyrgyzstan & 98 & 41.06 & 8.73 & & \\
\hline Female & Turkey & 96 & 35.32 & 9.37 & \multirow{2}{*}{4.227} & \multirow{2}{*}{$0.001 *$} \\
\hline Female & Kyrgyzstan & 108 & 44.34 & 11.82 & & \\
\hline All & Turkey & 197 & 36.89 & 9.83 & \multirow{2}{*}{3.741} & \multirow{2}{*}{$0.001 *$} \\
\hline All & Kyrgyzstan & 206 & 42.41 & 11.08 & & \\
\hline Female & Kyrgyzstan & 108 & 44.34 & 11.82 & \multirow{2}{*}{2.009} & \multirow{2}{*}{$0.047 *$} \\
\hline Male & Kyrgyzstan & 98 & 41.06 & 8.73 & & \\
\hline Female & Turkey & & 35.32 & 9.37 & \multirow{2}{*}{1.495} & \multirow{2}{*}{0.138} \\
\hline Male & Turkey & & 36.29 & 12.11 & & \\
\hline
\end{tabular}

When the humor styles of male Turkish and Kyrgyz students were examined, the results were similar to those of female students. Significant difference was observed between male students in participatory humor and aggressive humor. In participatory humor, the average of male Turkish students was found 39.94; that of male Kyrgyz students was 35.58 . The difference (4.36) between two groups was significant $(\mathrm{p}<0.006)$. Likewise, in aggressive humor, the difference (3.28) between the average scores of male Turkish students (26.61) and male Kyrgyz students $(29.89)$ was significant $(p<0.02)$. When the groups were evaluated in terms of positive and negative humor, no significant difference was found between the groups in terms of positive humor $(\mathrm{p}>0.05)$. In negative humor, however, the difference (4.51) between the average scores of male Turkish students (56.61) and male Kyrgyz students (61.12) was found significant $(\mathrm{p}<0.03)$.

\subsection{Comparison of Obedience Characteristics of the Students from Kyrgyzstan and Turkey}

The findings obtained from the comparison of Turkish and Kyrgyz students' obedience characteristics were shown in Table 8 . The difference between the average scores of the Turkish students (36.89) and the Kyrgyz students (42.41) was significant (5.52) in terms of the characteristics of obedience $(\mathrm{p}<0.001)$. Considering that the highest score to be obtained from the obedience scale is $80(16 \times 5)$, the Kyrgyz students can be said to have a level of obedience over the average. A significant difference in terms of obedience was found between male Turkish students (36.29) and male Kyrgyz students (41.06) $(p<0.001)$. Similarly, the difference between female Turkish students (35.32) and female Kyrgyz students (44.34) was statistically significant $(\mathrm{p}<0.001)$.

The difference between the average scores of female and male Turkish students was also examined. The average score of males and females were found 26.32 and 35.32, respectively; the difference was not significant $(p>0.05)$. On the other hand, the difference (3.28) between the average obedience scores of male (41.06) and female (44.34) Kyrgyz students was statistically significant $(\mathrm{p}<0.05)$.

\section{Discussion}

Individual differences between people cannot be denied; likewise, cultural differences are of importance to the 
same degree. Today, individuals belonging to different cultures meet more often, have close relations, and sometimes have to live together. The prerequisite for different people's living together is that they are aware of each other's differences and respect them. In close relationship of people from different cultures, knowing the attitudes people bring as a result of their cultural genetics will improve the relationship and make it more healthy and functional. Hareli [26] observed that understanding emotional expression correctly in human relations determines the reaction to be given and that this makes communication better and more useful. Thus, investigation of the similarities and differences between societies, those with closer cultural ties in particular, by social scientists through the studies and communicating the results with political, economic, and cultural authorities are of great importance.

This study aimed to compare anger, humor, and obedience behaviors of young people from two cultures that have close relations, share a common history, and have an increasing political, social, cultural, and economic cooperation.

In the dimension related to anger, three different and one similar characteristic of Kyrgyz and Turkish people were determined. Kyrgyz people and Turkish people show similar characteristics regarding suppressing their anger and expressing it. Although no previous study has focused on these two cultures, Naeimeh [33] has found similar results in terms of anger expression style in his study on Indian and Persian students. The results of this study reporting that Persian student got higher scores in continuous anger and Indian students got higher scores in anger control exhibit complete similarity to the results of our study. Based on our results, Turkish people had more continuous anger compared to the Kyrgyz people. In other words, the individuals living in the Turkish society are angrier than Kyrgyz people. Yet, Turkish people can control their anger better than Kyrgyz people. The difference in the anger control between two societies has been found to be significant. Adam [32] reported that people of European origin control anger behavior better than people of Asian origin. It cannot be said that Turkey is a European country but it can be claimed that Turkey's relation and interaction with Europe is greater compared to Kyrgyzstan. Similar results have been obtained in Smith's study [25] where Turkish university students were included in the sample. In that study, Smith [25] divided the sample into two and included Turkish students in the same group with Pakistani and Chinese students. Compared with the first group, which included the students from the United Kingdom and Finland, the students of Asian origin in the second group considered suppressing anger as superiority and nobility more often. Similar results have been obtained in Liu's sample [27] including the Chinese and Americans. While Americans preferred expressing their anger directly, the individuals in the Chinese sample preferred staying away from anger and expressing it in a less direct way. When the results of all these studies were evaluated, Turkish society exhibited characteristics of anger and anger expression partially similar to Western societies but it also had differences. This situation may be explained by the view that Turkish people are neither Westerner nor Asian and that they carry the characteristics of both cultures.

An interesting finding about the difference between two societies is the finding related to the gender factor. When Kyrgyz and Turkish women were compared, the difference was observed only in continuous anger; it was found that the women of two societies do not differ in suppressed anger, anger expressed towards others, and anger control. In this respect, it may be said that Turkish women are more Asian than Turkish men in terms of anger. In the comparison of the men of two societies, Turkish men scored significantly higher than their Kyrgyz counterparts in continuous anger and anger control while no difference was observed in suppressed anger and anger expressed towards others. Similar findings between genders were also observed by Ben-Zur [34]. In that study, differences were observed between the men and women in both Israeli and American societies about anger expression and continuous anger.

The results of this study concerning the anger factor indicated that anger and anger expression styles are affected by cultural structure. As much as the Turkish and Kyrgyz societies have similar characteristics resulting from cultural similarities, they have differences. The difference between two societies was more pronounced in continuous anger and anger control. Assuming that the Turkish society has more common characteristics with the individualist culture than the Kyrgyz society has, this difference is in agreement with with the results of several other studies. Puspakirana [28] explains the differences about anger and anger expression styles by arguing that Australia represents individualist culture and Indonesia represents collectivist culture. Similarly, Boiger [30] observed that Americans express anger based on the reaction models and perceptions compatible with the competitive and individualist culture and the objectives of this culture and that the Belgian culture does not affirm anger expression and interpreted that the differences between anger and anger expression are determined by the emotional models of the culture.

It is argued that people's understanding of humor is largely shaped by the culture in which they live. A style or subject of humor received in a positive way and accepted in one culture may not be approved in another culture and can even be found aggressive or humiliating. A subject of humor that makes the people of one culture laugh and amuses them may be meaningless for another society. It is inevitable that miscommunication happens when people coming from different societies live together and do not pay attention to each other's sense of humor. This 
situation may sometimes go beyond miscommunication and causes conflict and violence among people. The bitter result of an Englishman's action that is considered a joke in his own culture during a football game in a stadium in another country is the most striking example of this situation. The conclusion is as follows: People should enter into communication by having information about each other's sense and style of humor.

Significant differences have been found in the sense of humor in Kyrgyz and Turkish societies in this study. The differences about the sense of humor between the two societies were even more than those about anger. This situation may be explained by the fact that anger has also biological and physiological bases but that the cultural subtext of humor is more than that of anger. It has been observed that the positive and negative perceptions of humor among Kyrgyz and Turkish people were completely different. Turkish students had higher scores in positive humor while Kyrgyz students had higher scores in negative humor. Moreover, there were significant differences between the two societies in terms of participatory humor, aggressive humor, and self-annihilatory humor. Among humor styles, the only dimension in which no difference was found between the two societies was progressing humor. In this dimension, the people of two cultures have similar characteristics. Based on these explanations, it may be advised that Turkish and Kyrgyz persons who were introduced recently or who are at the initial stages of their relationship should not make jokes to each other.

The results of our study about humor were consistent with the results of several previous studies on Asian and Eastern societies. Blair [44] reported that humor is considered in the eastern societies as a profession and believed to be done by professionals and that those outside this profession prefer staying away from humor. Yue [45] have found that Chinese students defined humor as deviation from seriousness and with negative adjectives but humor was considered an indispensable part of daily life and defined with positive adjectives in Western societies, particularly in America.

In our study, it has been observed that the similarities in the sense of humor between Turkish and Kyrgyz women are more than that between men. While Turkish and Kyrgyz women have more similar styles in participatory, progressing, and self-annihilatory humor subjects, a difference in aggressive humor has been found. When participatory and progressing humor were categorized as positive humor and self-annihilatory humor as negative humor, Kyrgyz women had significantly higher scores in negative humor than their Turkish counterparts while no difference was found between the women of two societies in terms of positive humor. When the men of two societies were compared in terms of humor style, no difference was observed in progressing and self-annihilatory humor while significant differences were observed in participatory and aggressive humor. Similarly, Kyrgyz men had significantly higher scores in negative humor whereas the men of two societies had similar characteristics in positive humor. These results had similarities with the research findings of Chen [40] and Kazarian [47] as well as differences. Chen [40] has found differences between individualistic and collectivist life styles in favour of individualistic life style especially in positive humor where participatory and self-progressing humor were grouped. Assuming that Turkish society has a life style that is more individualistic than Kyrgyz society, the findings of our study were consistent with Chen's findings [40]. Kazarian [47] compared a sample from Armenia-Lebanon with that from Canada and Belgium. The sample from Armenia-Lebanon, which can be considered more collectivist compared to other group, scored lower in participatory and self-progressing humor.

In our study, submission and obedience were used as synonyms. The largest difference between the societies in question in our study was observed in this subject. In other words, when all of the characteristics of anger, humor, and submission for two societies were evaluated together, the least difference was observed in anger and the largest difference was observed in submission. The differences in humor were intermediate between these two. To summarize, the men and women of the Kyrgyz society were significantly more obedient than those in the Turkish society. This can be explained by the cultural history dating back to centuries ago when obedience was considered a positive characteristic. Besides, the form of government that has dominated the Kyrgyz society until the last 25 years can be said to have supported the culture of submission. We suggest that this subject to be investigated further by cultural anthropologists, sociologists, and political scientists.

An interesting finding in our study was that Turkish women were less obedient compared to Turkish men. Although it is not statistically significant, Turkish men can be said to be more obedient than Turkish women considering the arithmetic averages.

In many studies involving intercultural comparisons about obedience, it was observed that no significant differences were found between the levels of submissiveness in different cultures [65,66,67]. Studies have focused on variables that determine submission. In this respect, the tendency for obedience to a person with scientific personality was found higher in Western cultures while e tendency for obedience to a person with leadership and mystic personality and charismatic characteristics was found higher in Eastern cultures [67].

\section{Limitations and Suggestions}

In conclusion, we accept that our study has limitations in several aspects. Yet, we consider our study as important 
in that it takes attention to the necessity and need for more comprehensive social psychology studies of the Turkish and Central Asian societies. Above all, getting to know the cultures of the countries that we have historical cultural ties to and call for a closer political, economic, and cultural cooperation and having the peoples of those cultures to know us would strengthen "public diplomacy". The scientific effort in this subject will contribute to the eradication of vast prejudices that we still witness. Conducting such scientific studies in collaboration with Central Asian scientists will increase the reliability and influence of these studies.

\section{REFERENCES}

[1] Schiraldi, GR. And Kerr, HM. (2002) the anger management sourcebook. New York: McGraw Hill.

[2] O'Rourke, K. and Worzbyt, CJ. (1996). Support Groups for Children. Philadelphia, PA: Accelerated Development.

[3] Spielberger, CD., Jacobs, GA., Russell, S. and Crane, RS. (1983) Assessment of Anger: The State-Trait Anger Scale. In: JN Butcher, CD Spielberger, eds. Advances in Personality Assessment, vol 2. Hillsdale, NJ: Lawrence Erlbaum Associates, Inc.

[4] Özer, KA. (1994). Öfke, Kayg1 ve Depresyon Eğilimlerinin Bilişsel Alt Yapısıyla İlgili Bir Çalışma. Türk Psikoloji Dergisi, 9(31): 26-35.

[5] Lore, RK. And Schultz, LA. (1993).Control of Human Aggression: A Comparative Perspective. American Psychologist, 48(1): 16-25.

[6] Stephen, L. (2006) Social Psychology, Fourth Edition, New York: McGraw Hill Editions.

[7] Ellis, A. (1977) How to Control Your Anger Before It Controls You. Secaucus, N.J.: Carol Pub. Group. (pp 130).

[8] Dykeman, BF. (1995). The Social Cognitive Treatment of Anger and Aggression in Four Adolescents With Conduct Disorder. Journal of Instructional Psychology, 22: 194-203.

[9] Baron, RA. (1976). the Reduction of Human Aggression: A Field Study of The Influence of Incompatible Reactions. Journal of Applied Social Psychology, 6: 260-274.

[10] Gentry, WD. (2000) Anger Free. Ten Basic Steps to Maneging Your Anger. New York: Harper Collins Publisher Inc.

[11] Morgan, SP. (1998) Effect of Anger Coping Training on Aggressive Boys Attending a Behavioral Day Treatment Program. Hostra University Journey. UMI Company.

[12] Koestler, A. (1997) Mizah Yaratma Eylemi. (Çev: Sevinç Kabakçıoglu-Özcan Kabakçıoglu). İstanbul: İris Yayıncılık, Birinci Bask1. (pp. 10-11).

[13] Bergson, H., Meredith, G. and Sypher, W. (1956) Comedy: An Essay on Comedy. New York: Doubleday Anchor Books. (pp. 61-190).
[14] Yerlikaya, E. (2003) A Study on the Adaptation of Humor Styles Questionnaire. Unpublished Master Thesis, Adana: Cukurova University Institute of Social Sciences.

[15] Ford, TE., Katelyn A. McCreight \& Kyle Richardson. 2014. Affective Style, Humor Styles and Happiness. European Journal of Psychology 10. 451-463.

[16] Ferguson, MA. And Ford, T.E. (2008). "Disparagement Humor: A Theoretical and Empirical Review of Psychoanalytic, Superiority, And Social Identity Theories." Humor: International Journal of Humor Research 21.3, 283-312. Psychology and Behavioral Sciences Collection. Web. 12 Dec. 2015.

[17] Gilbert, P. and Allan S. (1994). Assertiveness, Submissive Behavior, and Social Comparison. British Journal of Clinical Psychology, 33: 295-306.

[18] Gander, MJ. and Gardiner, H. (1998). Çocuk ve Ergen Gelişlimi (Yayına Hazırlayan: Bekir Onur), Ankara: Imge Kitabevi.

[19] Grzyb, T. and Dolinski, D. (2017) Beliefs about Obedience Levels in Studies Conducted within the Milgram Paradigm: Better than Average Effect and Comparisons of Typical Behaviors by Residents of Various

[20] Pratto, F., Sidanius, J., Stallworth, LM. And Malle, BF. (1994). Social Dominance Orientation: A Personality Variable Predicting Social and Political Attitudes. Journal of personality and social psychology, 67(4): 741-763.

[21] Adorno, TW. Frenkel-Brunswik, E., Levinson, DJ. And Sanford, RN. (1950) The Authoritarian Personality. New York: Harper and Row (pp. 228).

[22] Doty, MR., Peterson, BE. And winter, DG. (1991). Threat and Authoritarianism in The United States, 1978-1987. Journal of Personality and Social Psychology, 61(4): $629-640$

[23] Dusay, MJ. And Dusay, KM. (1989) Transaactional Analysis. Editor: Corsini RJ, Veddig DN. Current psychotherapies. USA: E. E. Peacock. (pp. 288-291).

[24] Popov, LM. and Ustin, PN. (2016). Psychological Alienation Problem in Moral and Ethical Psychology of Personality. IEJME-Mathematics Education, 11(4): 787-797.

[25] Smith, PB., Easterbrook, MJ., Celikkol, GC., Chen, SX., Ping, H. and Rizwan, M. (2016). Cultural Variations in the Relationship between Anger Coping Styles, Depression, and Life Satisfaction. Journal of Cross-Cultural Psychology, 47(3): 441-456.

[26] Hareli, S., Kafetsios, K. and Hess, U. (2015). A Cross-Cultural Study on Emotion Expression and The Learning of Social Norms. Front. Psychol, 6: 1501.

[27] Liu, C. (2014). Chinese, Why Don't You Show Your Anger? - A Comparative Study between Chinese and Americans in Expressing Anger. International Journal of Social Science and Humanity, 4(3): 206-209.

[28] Puspakirana, I. and Setiawan, S. (2014). A Study of Cross-Cultural Understanding of Showing Anger in Indonesian and Australian Families. Language Horizon, 2 (2): $1-8$ 
[29] Park, J., Kitayama, S., Markus, HR., Coe, CL., Miyamoto, Y., Karasawa, M., Curhan, KB. Love, GD., Kawakami, N., Boylan, JM. And Ryff, CD. (2013). Social Status and Anger Expression: The Cultural Moderation Hypothesis. Emotion, 13 (6): 1122. (10.1037/a0034273.http://doi.org/10.1037/a0 034273)

[30] Boiger, M., De Deyne, S. and Mesquita, B. (2013). Emotions in "The World": Cultural Practices, Products, and Meanings of Anger and Shame in Two Individualist Cultures. Frontiers in psychology, 4: 867.

[31] Moscoso, MS. and Spielberger, CD. (2011). Cross-Cultural Assessment of Emotions: The Expression of Anger. Revista de Psicología, 29(2): 343-360.

[32] Adam, H., Shirako, A. and Maddux, WW. (2010). Cultural Variance in the Interpersonal Effects of Anger in Negotiations. Psychological Science, 21 (6): 882-889.

[33] Naeimeh, M. and Usha, R. (2010). Cross-Cultural Study of Stress and Anger. Procedia Social and Behavioral Sciences, 5: 1765-1769.

[34] Ben-Zur H. and Zeidner M. (1988). Sex Differences in Anxiety, Curiosity, and Anger: A cross-Cultural Study. Sex Roles, 19 (5-6): 335-347.

[35] Edwards, KR. and Martin, RA. (2012). Do Humorous People Take Poorer Care of Their Health? Associations between Humor Styles and Substance Use. Europe's Journal of Psychology, 8: 1-12.

[36] Dozois, DJA., Martin, RA. and Faulkner, B. (2013). Early Maladaptive Schemas, Styles of Humor, and Aggression. Humor: International Journal of Humor Research, 26(1): 97-116.

[37] Veselka, L., Schermer, JA. Martin, RA. and Vernon, PA. (2010). Laughter and Resiliency: A behavioral Genetic Study of Humor Styles and Mental Toughness. Twin Research and Human Genetics, 13: 442-449.

[38] Martin, RA. (2014) Humor and Gender: An Overview of Psychological Research. In Chiaro D, Baccolini R (Eds.), Gender and humor: Interdisciplinary and international perspectives New York, NY, USA: Routledge. (pp. 123-146).

[39] Kazarian, SS., Moghnie, L. and Martin, RA. (2010). Perceived Parental Warmth and Rejection in Childhood as Predictors of Humor Styles and Subjective Happiness. Europe's Journal of Psychology, 3: 71-93.

[40] Chen, G., Watkins, D. and Martin, RA. (2013). Sense of Humor in China: The Role of Individualism, Collectivism, and Facework. Psychologia; 56: 57-70.

[41] Veselka, L., Schermer, JA. Martin, RA., Cherkas, LF. Spector, TD. And Vernon, PA. (2010). A Behavioral Genetic Study of Relationships between Humor Styles and the Six HEXACO Personality Factors. Europe's Journal of Psychology, 3: 9-33.

[42] Caird, S. and Martin, RA. (2014). Relationship-Focused Humor Styles and Relationship Satisfaction in Dating Couples: A Repeated-Measures Design. Humor: International Journal of Humor Research, 27(2): 227-247.

[43] Rudnick, A., Kohn, PM., Edwards, KR., Podnar, D., Caird, S. and Martin, RA. (2014). Humour-Related Interventions for People with Mental Illness: A Randomized Controlled
Pilot Study. Community Mental Health Journal, 50: 737-742.

[44] Blair, W. and Hill, H. (1978) America's Humor: From Poor Richard to Doonesbury. New York: Oxford Univ. Press (pp. 559).

[45] Yue, X., Jiang, F., Lu, S. and Hiranandani, N. (2016). To Be or Not To Be Humorous: Cross Cultural Perspectives on Humor. Front Psychol, 7: 1495-1498.

[46] Chen, G-H., Martin, RA. (2007). A Comparison of Humor Styles, Coping Humor, and Mental Health Between Chinese and Canadian University Students. Humor International Journal of Humor Research, 20(3): 215-234.

[47] Kazarian, SS. and Martin, RA. (2006). Humor Styles, Culture-Related Personality, Well-Being, and Family Adjustment among Armenians in Lebanon. Humor: International Journal of Humor Research, 19: 405-423.

[48] Ford, TE., Lappi, SK. and Holden, CJ. (2016). Personality, Humor Styles and Happiness: Happy People Have Positive Humor Styles. Eur J Psychol, 12(3): 320-337.

[49] Hampes W. (2016). The Relationship between Humor Styles and Forgiveness. Europe's Journal Psychology. 12(3): 338-347.

[50] Rnic, K., Dozois, DJ. And Martin, RA. (2016). Cognitive Distortions, Humor Styles, and Depression. Europe's Journal Psychology, 12(3): 348-362.

[51] Zeigler-Hill, V., McCabe, GA. and Vrabel, JK. (2016). The Dark Side of Humor: DSM-5 Pathological Personality Traits and Humor Styles. Europe's Journal of Psychology, 12(3): 363-376.

[52] Fox, CL., Hunter, SC. and Jones, SE. (2016). Longitudinal Associations between Humor Styles and Psychosocial Adjustment in Adolescence. Europe's Journal of Psychology, 12(3): 377-389.

[53] DiDonato, TE. And Jakubiak, BK. (2016). Strategically Funny: Romantic Motives Affect Humor Style in Relationship Initiation. Kuiper N, ed. Europe's Journal of Psychology, 12(3): 390-405.

[54] Saroglou, V., Lacour, C. and Demeure, M. (2010). Bad Humor, Bad Marriage: Humor Styles in Divorced and Married Couples. Europe's Journal of Psychology, 3: 94-121.

[55] Hahn, CM. and Campbell, LJ. (2016). Birds of a Feather Laugh Together: An Investigation of Humor Style Similarity in Married Couples. Europe's Journal of Psychology, 12(3): 8-19.

[56] Freedman, J., Sears, DO. And Carlsmith, JM. (1981) Social Psychology. 4th ed. Englewood Cliffs, NJ: Prentice-Hall. (pp. 128-131).

[57] Aronson, E., Wilson, TD. And Akert, RM. (1997) Social Psychology. 2nd. ed. New York: Addison - Wesley Educational Publishers Inc., pp. 315-318.

[58] Hennessy, DA. And Wiesenthal, DL. (1999). Traffic Congestion, Driver Stress and Driver Aggression. Aggressive Behavior, 25: 409-423.

[59] Campbell, A., Muncer, S., Guy, A. and Banim M. (1996). Social Representations of Aggression: Crossing the Sex 
Barrier. European Journal of Social Psychology, 26: 135-147.

[60] Agrawal, S. and Williams M. (2017) Robot Authority and Human Obedience: A Study of Human Behaviour Using a Robot Security Guard. İnternational Conference on Human-Robot Interaction Vienna, Austria, March 06-09, pp. $57-58$

[61] Grzyb T, Jakub D, Trojanowski J, Bar-Tal Y. (2017). Cognitive Structuring and Obedience toward Authority. Personality and Individual Differences, 289-291 (https://doi.org/10.1016/j.paid.2017.08.032).

[62] Breckler, SJ., Olson, JM. and Wiggins, EC. (2006) Social Psychology Alive. Belmont: Thomson Higher Education (p. 316).

[63] Middendorp, CP. and Meloen, JD. (1991). Social Class, Authoritarianism and Directiveness. European Journal of Political Research, 20(2): 213.

[64] Pozzi, M., Fattori, F., Bocchiaro, P. and Alfieri, S. (2014). Do The Right Thing! A Study on Social Representation of Obedience and Disobedience. New Ideas in Psychology, 35(1): 18-27.
[65] Shanab, ME. and Yahya, KA. (1977). A Behavioral Study of Obedience in Children. Journal of Personality and Social Psychology, 35(7): 530-536.

[66] ME. and Yahya, KA. (1978). A Cross-Cultural Study of Obedience. Bulletin of the Psychonomic Socety, 11(4): 267-269.

[67] Blass, T. (2012). A Cross-Cultural Comparison of Studies of Obedience Using The Milgram Paradigm: A review. Social and Personality Psychology Compass, 6 (2): 196-205.

[68] Martin, RA., Puhlik-Doris, P., Larsen, G., Gray, J. and Weir, K. (2003). Individual Differences in Uses of Humor and Their Relation to Psychological Well-Being: Development of the Humor Styles Questionnaire. Journal of Research in Personality, 37, 48-75.

(http://dx.doi.org/10.1016/S0092-6566(02)00534-2)

[69] Gilbert, DT. (1991). How Mental Systems Believe. American Psychologist, 46: 107-119.

[70] Savaşır, I. and Şahin, NH. (1997) Boyun Eğici Davranışlar Ölçeği. Bilişsel-Davranışçı Terapilerde Değerlendirme: S1k Kullanılan Ölçekler. Ankara: Özyurt Matbaacılık, (pp. 100-103). 